Article

\title{
The Case History of an Insect Infestation Revealed Using $X$-ray Computed Tomography and Implications for Museum Collections Management Decisions
}

\author{
Shivani Arbat ${ }^{1,2}$, Brian T. Forschler ${ }^{1, *, \dagger}$, Annelies M. Mondi ${ }^{3, \dagger}$ and Ajay Sharma ${ }^{4}$ \\ 1 Department of Entomology, University of Georgia, Athens, GA 30602, USA; sga64681@uga.edu \\ 2 Department of Computer Science, University of Georgia, Athens, GA 30602, USA; \\ 3 Georgia Museum of Art, University of Georgia, Athens, GA 30602, USA; amondi@uga.edu \\ 4 College of Veterinary Medicine, University of Georgia, Athens, GA 30602, USA; as7930@uga.edu \\ * Correspondence: bfor@uga.edu \\ + These authors contributed equally to this work.
}

check for

updates

Citation: Arbat, S.; Mondi, A.M.; Sharma, A.; Forschler, B.T. The Case History of an Insect Infestation Revealed Using X-ray Computed Tomography and Implications for Museum Collections Management Decisions. Heritage 2021, 4, 1016-1025. https://doi.org/10.3390/

heritage 4030056

Academic Editor: Roberto Scopigno

Received: 9 May 2021

Accepted: 16 June 2021

Published: 22 June 2021

Publisher's Note: MDPI stays neutral with regard to jurisdictional claims in published maps and institutional affiliations.

Copyright: (c) 2021 by the authors. Licensee MDPI, Basel, Switzerland. This article is an open access article distributed under the terms and conditions of the Creative Commons Attribution (CC BY) license (https:/ / creativecommons.org/licenses/by/ $4.0 /)$.

\begin{abstract}
The protection of cultural heritage and property is a significant and critical task that requires collaboration and expertise in a variety of disciplines. Of the many risk factors, insect infestation is one cause of deterioration and loss. At a large, state university, disparate departments, ranging from Facilities Management to the Entomology Department and Veterinary Medicine, assisted the university museum in identifying a drywood termite infestation, determining the extent of loss and developing a plan to prevent or mitigate future infestations. Our group was able to determine the extent and severity of a drywood termite infestation in the museum storage vault through visual inspection and X-ray computed tomography (CT). This paper describes the process and heuristics of identifying and estimating the amount of active/inactive termite infestations in the art frames as well as visualizing a 3-dimensional structure to learn the extent of infestation. This interdisciplinary collaboration and effectual use of tomography enabled our group to determine the condition of several art frames through non-invasive means and develop a plan of action to identify and prevent future insect incursions within the museum.
\end{abstract}

Keywords: termite; infestation; art frame collections; museology; 3D reconstruction; volume estimation; X-ray tomography

\section{Introduction}

Termites are a diverse group of insects best known for the pest status attributed to a small portion of the over 3000 described species [1,2]. There are 28 invasive species known to be transported by human commercial activity, with the most notorious being the West Indian drywood termite, Crytotermes brevis (Walker) [3]. Drywood termites (family: Kaoltermitidae) obtain all the water required to sustain life from their food and the atmosphere while completing their entire life history inside a single piece of wood [1]. C. brevis evolved in the deserts of western South America, enabling them to survive the dry conditions of the built environment [4], and is known for feeding on works of art that are purchased, traded and maintained in personal or public collections [3].

In April of 2019, as part of the Standard Operating Procedure (SOP) of the University of Georgia (UGA) Termite Management Demonstration Project, the Household and Structural Entomology Research Program (HSERP) at the University of Georgia (UGA) received notice from the Facilities Management Division (FMD) of a termite infestation at the Georgia Museum of Art (GMOA). HSERP inspectors were directed to an assembly of insect wings on the floor of the GMOA collections vault (Figure 1a,b). A tentative, on-site identification was drywood termites based on examination of the wings and a few desiccated adult termites. Visual inspection of the art frames stored in the immediate 
vicinity resulted in the identification of a few drywood termite fecal pellets on two picture frames (Figure 1c). The upper-most frame was identified as infested through observation of one small (1 mm diameter) 'knock-out hole' (Figure 1d). These observations led to discussions with the GMOA staff, College of Veterinary Medicine, and the Entomology Department in a collaborative effort to determine the extent of the termite damage to that frame and the extent of infestation to other items in the vault. The infested frame housed a gouache painting on paper created sometime in the mid-19th to early 20th century by British-born American artist George Henry Boughton. The frame itself was made of gilded wood and manufactured in the latter half of the twentieth century. Unlike many of the other frames that were stored in close proximity, which is ornately carved and date as far back as the 18th century, the infested frame is of a simple design and relatively new. The entire collection of framed works on paper housed in this area of the vault is on extended loan to the museum from an individual collector. The museum's staff, responsible for protecting all works under its stewardship, required information on the scope and potential for spread of the newly discovered infestation to enumerate an appropriate course of action.

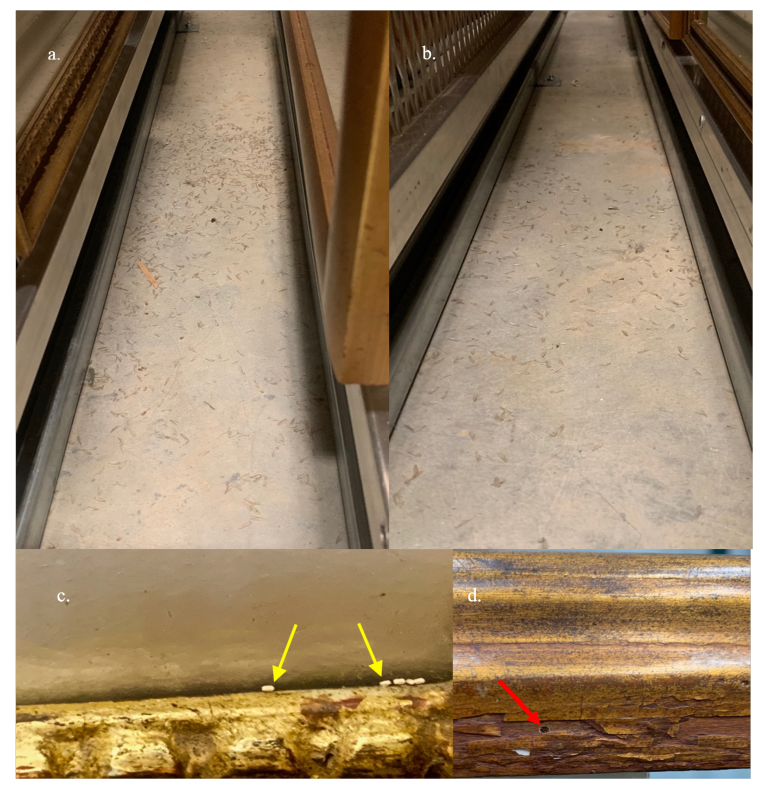

Figure 1. $(\mathbf{a}, \mathbf{b})$ Two rows of the vault floor showing the first sign of termite infestation-discarded termite wings. (c) yellow arrows - the drywood termite pellets, $1 \mathrm{~mm}$ in length, are shown on edge of the picture frame and (d) red arrow-the 'knock-out' hole, $1 \mathrm{~mm}$ in diameter, on the lower exterior portion of the frame.

The immediate question concerned the painting and its potential for being damaged by the termites. The probability of damage to the painting was small, given that the infestation was undoubtedly initiated prior to receiving the loan and had been ongoing for at least 15 years, the length of time that the art was in the vault. The decision was to err on the side of caution and isolate the painting from the frame. The process of removing the painting revealed numerous drywood termite fecal pellets—six-sided, dry and hard-resembling and having the texture of grains of sand, which confirmed the infestation. The next question involved justification for salvaging the frame and reviewing options for exterminating the insects without damage to the frame. Determining the extent of the infestation was not possible without dismantling the frame, and, therefore, the option of X-ray computed tomography was pursued with the cooperation of the UGA School of Veterinary Medicine who provided access to their Siemens Somatom Sensation 64 slice CT scanner. 


\section{Methods and Materials}

The termite-infested frame and 4 additional frames suspected of being compromised by insects were scanned, using the Siemens Sensation 64 CT unit, which was designed for animal tissues, not wood or works of art [5]. The 3D reconstruction of the art frame's internal structure involved two basic steps: CT imaging and image processing. The process used to generate the 3D renditions is outlined in Figure 2.

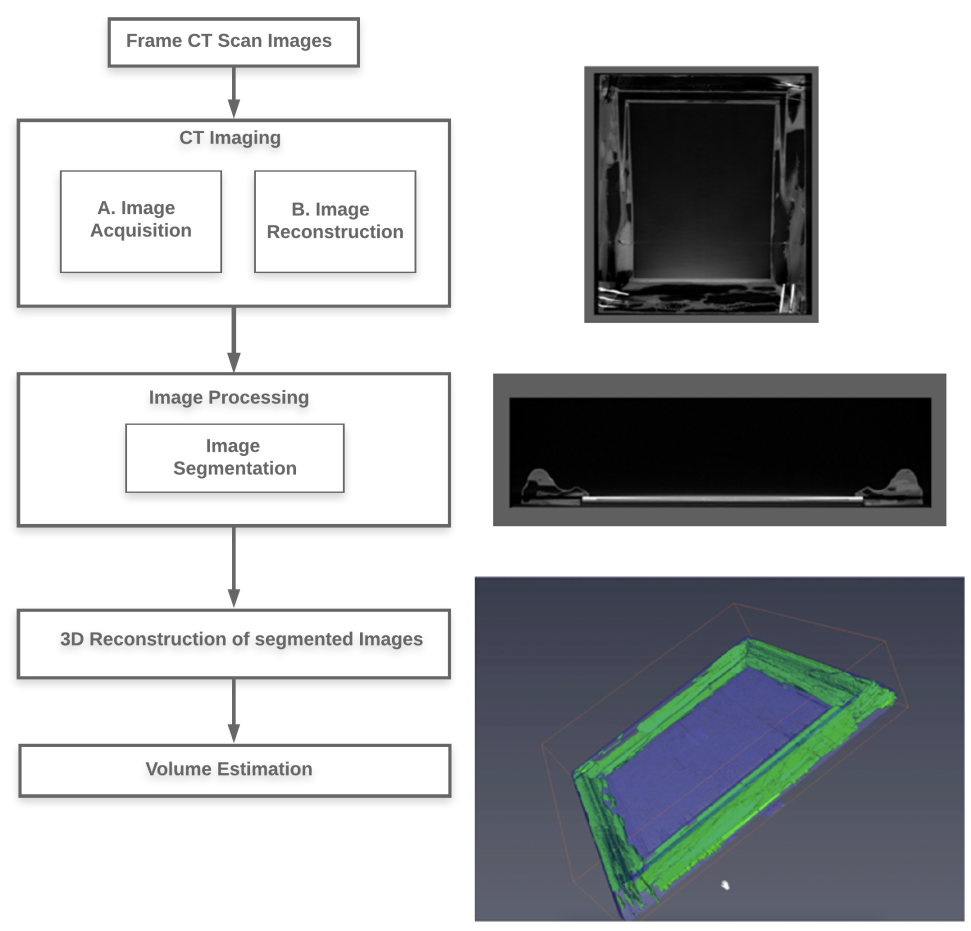

Figure 2. Step-by-step guide for 3D structure generation and volume estimation.

\subsection{CT Imaging}

The DICOM images generated by the Siemens Sensation 64 CT were on a transverse plane, using an X-ray tube current of $152 \mathrm{~mA}$ and peak voltage of $120 \mathrm{kVP}$ to a focal spot of $1.2 \mathrm{~mm}$ that was rotated clockwise (source-to-detector distance $=104 \mathrm{~cm}$ and source-tosample distance $=57 \mathrm{~cm}$ ) to obtain 1040 images per art frame. The exposure time for each image was $190 \mathrm{~ms}$, generating an image of $512 \times 512$ pixels with pixels sized at $1.27 \mathrm{~mm}^{2}$, providing an image thickness of $0.6 \mathrm{~mm}$. We examined several programs for manipulating the CT images, including Slicer 3D and Osirix MD, before deciding on Avizo [6]. Avizo provided a user-friendly interface and the option for easy manipulation of the data to create digital models, revealing the extent of the insect feeding activity, presence of live insects, and metrics for calculating the volume of wood removed.

\subsection{Image Processing}

All fields and options we mention can be viewed in tree form in the Project View window on the Avizo main page. Individual DICOM images were imported to the Avizo Program, using the 'File/Open Data' option and saved in the .am format. In the Project View option, we created a new object 'Ortho Slice' to visualize each DICOM image as an orthogonal slice. The 'Bounding Box' option was used to remove the CT scan bed area and other extraneous parts from all DICOM images. The bounding box was a rectangular, axis-aligned volume in 3D space that encompassed the object of interest [6], in our case, the art frame. We next created a label object using the field 'Labels' and attached it to the .am data to permit image segmentation on a defined series of DICOM images, in our case, each of the four art frames. Image segmentation can be achieved by the threshold 
technique, boundary based methods, region-based methods, and hybrid techniques [7]. We used the threshold technique [8] to generate segmentation maps that identified objects into Regions of Interest (RoI) including the following titles:

Exterior - the area outside of the picture frame. Areas marked as 'Exterior' did not contribute to calculation of volume attributed to the wooden frame or insect activity; Interior - the wooden area of the picture frame;

Insect activity - areas selected from the interior RoI representing wood missing due to feeding and excavation. The presence of live insects was revealed by high intensity pixels not attributed to the RoI 'nails' and were placed in the 'Insect Activity' RoI (Figure 3a);

Nails - any metal object captured inside the art frames was marked as 'Exterior' (Figure 3b);

Assumption - data assumed to connect galleries not shown in individual images and confirmed by visual examination of the actual wooden frame;

Other anomalies - any area in non-wooden structures of an art frame (Figure 3c).

Segmentation was accomplished at the basic unit of a pixel. The Threshold, and Magic Wand tools in the Segmentation Editor were used to select a defined range of pixel intensity for each RoI. The Avizo program has the option to provide a range of 8-bit signed integers to automatically assign pixels to a RoI, using the Magic Wand tool. Threshold, and Magic Wand both provide a multi-handled slider bar to select a range of pixel intensities for each RoI from a histogram of pixel intensity values that are applied to all images within the bounding box. The unpredictable pattern of insect activity proved difficult for both the Threshold and Magic Wand tools to correctly identify all insect-related pixels in an image. Thus, individual images were examined to identify the missed pixels in each RoI, and manual selection was performed using the Brush tool in the Segmentation Editor to connect any program-missed pixels. Manual image segmentation using the Brush tool was a time-consuming task to connect insect galleries in all four frames, respectively. Yet, there was considerable time savings in using those tools to properly identify $80 \%$ of the pixels in the insect activity RoI.

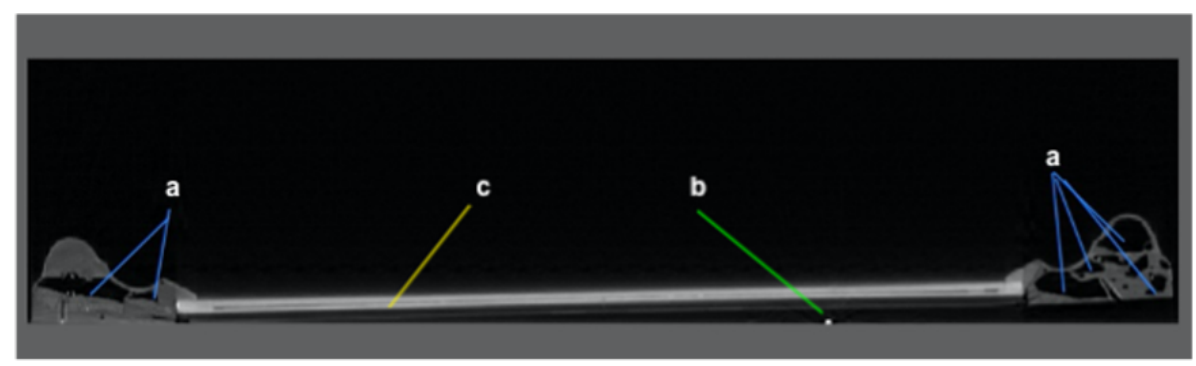

Figure 3. Region classification: (a) insect activity, (b) nails, or (c) other anomalies, which appear like insect activity in non-wooden structures of frame.

\subsection{D Image Reconstruction}

A 3D structure was assembled from the segmented regions, using the 'Generate Surface' field. We created a 'GenerateSurface' / 'Surface View' object and attached it to the 'Labels' field, which allowed creation of 3D renditions of the art frame by selecting RoI in 'Surface View' object properties. Figures 4-6 depicts 3D views assembled from the segmented regions. 


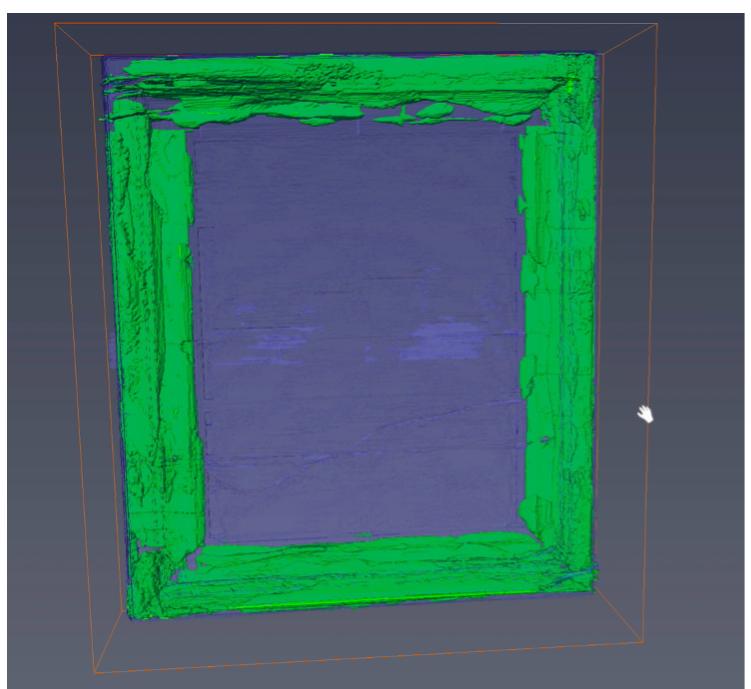

Figure 4. Avizo [6] 3D reconstruction of the art frame in $\mathrm{XY}$ axis view, representing the front of the art frame.

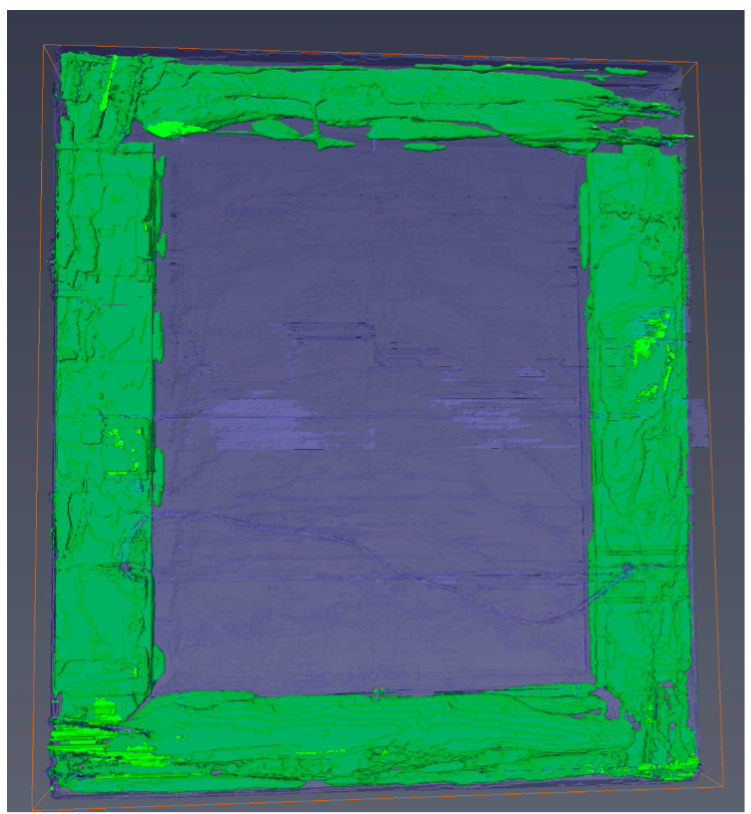

Figure 5. Avizo [6] 3D reconstruction of the art frame in XY axis view (rotated), representing the back of the art frame. 


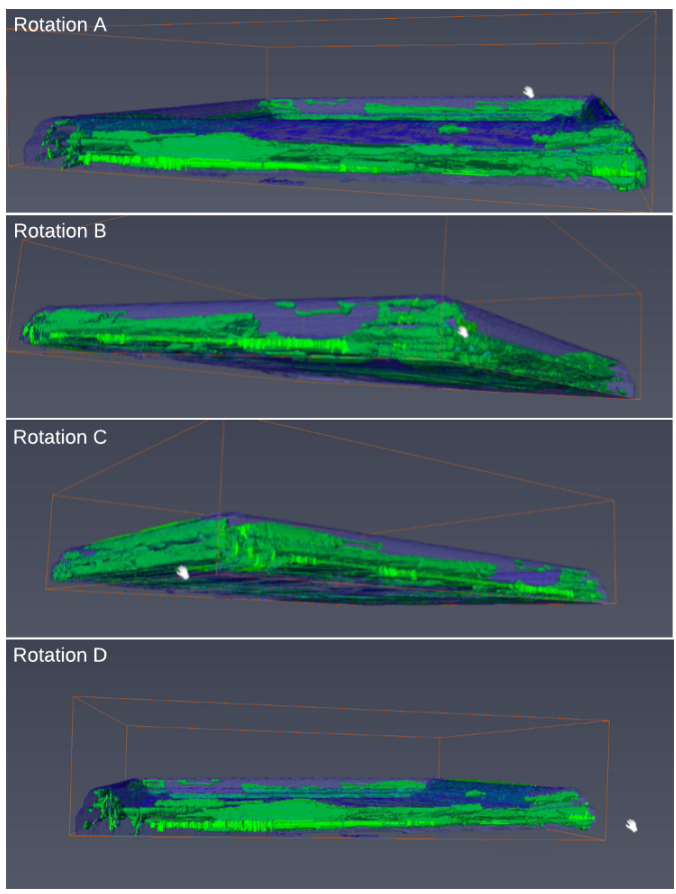

Figure 6. Avizo [6] 3D reconstruction of the frame in $\mathrm{YZ}$ axis view, representing the lower edge of the frame. Insect infestation can be found around the corners and edges of the frame.

\subsection{Volume Estimation}

The volume of wood removed was determined using the volume and statistics measurement feature of Avizo [6] under 'Segmentation/Material Statistics' with units set in the Unit Management option. RoI volume was determined by multiplying the pixel count by the distance between images $(0.6 \mathrm{~mm})$ to obtain a $1.27 \times 1.27 \times 0.6 \mathrm{~mm}^{3}$ voxel. Related voxels within each bounding box were summed to generate a volume. The percentage of volume removed by insects $(\mathrm{V})$ was calculated using the following formula:

$$
\begin{gathered}
V_{\%}=\frac{t a_{\text {total insect activity pixels }}}{t b_{\text {total wooden frame pixels }}} * 100 \\
t a_{\text {total insect activity pixels }}=q+r \\
t b_{\text {total wooden frame pixels }}=p+q+r
\end{gathered}
$$

where

$V$ is the proportional volume of wood removed by insects;

$p$ is the sum of pixels from the interior RoI;

$q$ is the sum of pixels from the insect activity RoI;

$r$ is the pixel volume from RoI insect assumptions.

\section{Results and Discussion}

The CT scans of art frames illuminated individual termites (Figure 7) in the infested frame, corroborating previous work that active insect infestations can be identified using that technology [9], while providing confidence in declaring the four other frames infestation-free without destructively sampling those frames or works of art. In addition, we could categorize the current or former insect activity in each frame as beetles or termites based on the morphology of the galleries (Figure 7). The percentage of wood volume 
removed by termite activity in the infested frame was $23.62 \%$ (refer Table 1), while the percentages of loss in the four frames formerly infested with beetles amounted to $1.2 \%, 1.7 \%$, $0.016 \%$ and $0 \%$, respectively. That $23.62 \%$ represents a significant amount of loss in the art frame infested with termites. Yet, with the exception of a few locations sporting $2 \mathrm{~mm}$ diameter knock-out holes along the frame exterior, the art frame appeared intact and its exterior aesthetic quality was not diminished. Except for a few locations where the wood was very thin below the surface gilding, there was no serious structural compromise. The volume of wood removed was calculated to be $2525.0 \mathrm{~cm}^{3}$, assuming 1 voxel represents $0.00096 \mathrm{~cm}^{3}$ $\left(1.27 \times 1.27 \times 0.6 \mathrm{~mm}^{3}\right)$.

Table 1. Summary of pixel counts used to calculate the percent volume of wood removed, using the Avizo program.

\begin{tabular}{cccc}
\hline Material & Material Color & Pixel Count & Volume in cm $^{\mathbf{3}}$ \\
\hline Wooden Frame & Blue, Transparent & $8,433,205$ & 8161.14 \\
\hline Insect Activity & Light Green, Solid Color & $2,609,172$ & 2525.00 \\
\hline V\% & 23.62 & & \\
\hline
\end{tabular}
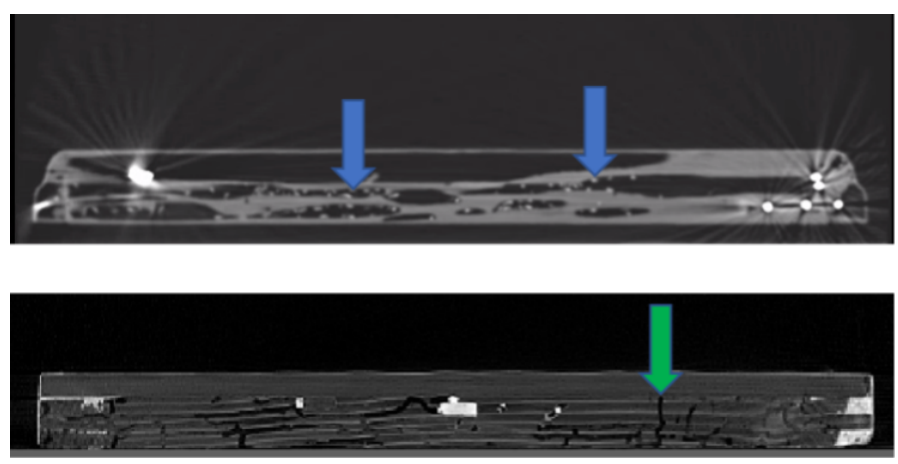

Figure 7. A view of the infested picture frame showing living termites, appearing as white dots, in their 'galleries' (just below the blue arrows). The bright, radiating white areas are nails and other metal objects. In contrast, the lower image shows another picture frame with beetle galleries that are no longer active (just below the green arrow).

The desiccated adult specimens (swarmers) collected on the initial inspection verified the insects as Cryptotermes brevis (Walker), the West Indian drywood termite. The biology of this insect clearly indicated the possibility that the adults that exited the infested picture frame could infest other wooden objects in the vault. This fact provoked the collections management staff to review and augment their Integrated Pest Management (IPM) plans and to begin developing a Standard Operating Procedure (SOP) for inspecting and possibly quarantining framed works, textiles, folk art and possibly furniture or any other objects that might be susceptible to insect infestation, before bringing these works into the collection storage rooms.

The collections management staff worked with the deputy director and curator in consultation with a local fine arts conservator to develop an action plan to safeguard the work of art housed within the infested frame and to protect other historical frames and works of art stored in the same vault. The staff was particularly concerned about the materials in this storage room because the majority of the objects are works on paper housed in antique wooden frames, some dating as early as the eighteenth century. In addition, the infested work and the other works of art in this storage room are not owned by the museum, but on extended loan from a private collection. Thus, the museum staff needed to make a formal proposal to the lender for the treatment of the objects. The museum staff reviewed treatment suggestions from the Entomology Department and a fine arts conservator, and considered several methods of treatment, including freezing the objects or placing 
them in an anoxic environment and using nitrogen gas to exterminate the insects [10-12]. Heating the work to an extreme temperature to kill the termites was not considered, as that approach would have a negative effect on the wood and gilding.

Regarding the infested frame, with permission from the lender, the work of art was removed from the frame and the infested frame was immediately removed from the museum building. Given the amount of insect damage to the frame, its owner decided to donate it to the Department of Entomology for study. Weighing the time and cost associated with treatment of the numerous other frames in the collection and the current curatorial preference to have works on paper stored in archival boxes rather than in the antique frames, the staff of the museum decided to unframe the over 1000 works on paper in the vault and return the frames to the lender. Unframing the works of art has the added benefit of making them more accessible for examination by researchers. This approach also removed the risk of further swarms of the termites that may have infested additional frames in the collection.

\section{Conclusions}

The employment of X-ray technologies with wooden artifacts or in situ logs for nondestructive identification of insect activity continues to show a broad range of applications [13-16]. This study demonstrates that computed tomography using medical-grade equipment and commercially available computer programs can provide a reliable method of screening works of art made of wood or housed in wood frames for the presence of active insect infestation. The philosophy of Integrated Pest Management (IPM) describes a biology-centric, multidisciplinary, collaborative effort to mitigate depredations caused by pest infestations $[17,18]$. Museum programs must, within the constraints afforded by operating budgets, protect their holdings from pests; this case history provides a blueprint for establishing agreements to facilitate IPM efforts.

The cryptic nature of wood-infesting insects and the determination of active infestations has long vexed museums and collectors [19]. The storage room that was the focus of the insect infestation described in this work provided environmental conditions (70 ${ }^{\circ} \mathrm{F}$ range $+/-5^{\circ} \mathrm{F}$ and $\mathrm{RH} 44-57 \%$ ) intended to safely maintain the works of art while allaying pest populations. A cautionary tale arises from the fact that those conditions that were meant to safeguard the collection from insect infestations, mold and other dangers were sufficient for the West Indian drywood termite colony to maintain their life support requirements for 15 years in museum custody, illustrating the need to be proactive when accepting art into a collection. The biology of this notoriously invasive termite hints that those aforementioned relatively low temperature and humidity conditions undoubtedly contributed to the slow growth and reproduction of this infestation [20,21]. The time frame from acquisition until identification of the infestation is within the 7-30 year age limit for termite adults [22]. However, no adult termites (king or queen) were observed when the art frame was dismantled. The release of alates (winged adults) by this colony suggests that the original king and queen, brought in with the frame, expired, which triggered production of swarmers whose flight led to the identification of the presence of this enigmatic infestation [23]. The museum decision-making process was aided by the accumulation of entomological evidence that the insects were brought into the storage room over a decade earlier, rather than initiated while in museum custody.

The CT scan of the infested frame illuminated individual termites (Figure 7), corroborating previous studies that live, wood-infesting insects can be identified using X-ray technology [9]. Comparing images of the termite-infested frame to the other four art frames allowed the designation of the other frames as infestation-free without destructive sampling. In addition, we could determine the causal agent as beetles based on the morphology of the galleries (Figure 7). Lastly, the tomography using a commercially available program on images taken with a medical-grade scanner demonstrated that the volume of wood removed by termite activity in the infested art frame was a significant amount although the frame showed little to no damage to the exterior surface. The information obtained by CT imaging provided a valuable, non-invasive methodology for identifying areas of in- 
terest important in the decision-making process when planning restoration, remediation, archiving and/or accepting art objects into a collection. For over a year, the COVID-19 global pandemic caused museums closures across the world. Extended museum shutdown possesses risk to increased pest infestation [24]. However, in some instances, the closures afforded museum staff the time to thoroughly examine and clean their collections, thereby preventing possible insect infestations. The non-invasive techniques discussed in this paper can help identify active insect activity in museum collections. We recommend museums to consider establishing an IPM partnership with organizations that have a CT scanner, an entomologist, and tomography programmer when developing SOPs to screen acquisitions and identify active infestations in current collections. The collaboration of specialists in various disciplines and the use of advanced technological tools can greatly enhance the preservation of our shared cultural heritage.

Author Contributions: Conceptualization, B.T.F. and A.M.M.; methodology, S.A.; software, S.A.; validation, S.A., B.T.F. and A.M.M.; formal analysis, B.T.F. and A.M.M.; investigation, B.T.F.; resources, B.T.F., A.M.M. and A.S.; data curation, S.A. and B.T.F.; writing-original draft preparation, S.A. and B.T.F.; writing-review and editing, S.A., B.T.F., A.M.M. and A.S.; visualization, S.A.; supervision, B.T.F. and A.M.M.; project administration, B.T.F.; funding acquisition, B.T.F. All authors have read and agreed to the published version of the manuscript.

Funding: We would like to acknowledge the Georgia Department of Agriculture (grant number FP00005972) for providing the financial support that made this project possible.

Institutional Review Board Statement: There were no human or animal subjects used in this research.

Informed Consent Statement: There were no human or animal subjects used in this research.

Data Availability Statement: Inquires for supporting data should be addressed to the corresponding author atbfor@uga.edu.

Conflicts of Interest: The authors declare no conflict of interest.The funders had no role in the design of the study; in the collection, analyses, or interpretation of data; in the writing of the manuscript, or in the decision to publish the results.

\begin{tabular}{|c|c|}
\hline \\
\hline \multicolumn{2}{|c|}{ Abbreviations } \\
\hline $\mathrm{CT}$ & Computed Tomography \\
\hline $2 \mathrm{D}$ & Two Dimensional \\
\hline $3 \mathrm{D}$ & Three Dimensional \\
\hline DICOM & Digital Imaging and Communications in Medicine \\
\hline SOP & Standard Operating Procedure \\
\hline $\mathrm{RH}$ & Relative Humidity \\
\hline GMOA & Georgia Museum of Art \\
\hline UGA & The University of Georgia \\
\hline RoI & Region of Interest \\
\hline IPM & Integrated Pest Management \\
\hline
\end{tabular}

\section{References}

1. Krishna, K.; Grimaldi, D.A.; Krishna, V.; Engel, M.S. Treatise on the Isoptera of the world: Termitidae (part three), incertae sedis, taxa excluded from Isoptera. Bull. Am. Mus. Nat. Hist. 2013, 2013, 1989-2433. [CrossRef]

2. Bignell, D.E.; Roisin, Y.; Lo, N. Biology of Termites: A Modern Synthesis; Springer Science \& Business Media: Berlin, Germany, 2010.

3. Evans, T.A.; Forschler, B.T.; Grace, J.K. Biology of invasive termites: a worldwide review. Ann. Rev. Entomol. 2013, 58, 455-474. [CrossRef]

4. Scheffrahn, R.H.; Křeček, J.; Ripa, R.; Luppichini, P. Endemic origin and vast anthropogenic dispersal of the West Indian drywood termite. Biol. Invas. 2009, 11, 787-799. [CrossRef]

5. Albertin, F.; Bettuzzi, M.; Brancaccio, R.; Morigi, M.P.; Casali, F. X-ray computed tomography in situ: An opportunity for museums and restoration laboratories. Heritage 2019, 2, 2028-2038. [CrossRef] 
6. Avizo. 3D Visualization \& Analysis Software. 2021. Available online: https://www.thermofisher.com/us/en/home/industrial/ electron-microscopy/electron-microscopy-instruments-workflow-solutions/3d-visualization-analysis-software.html (accessed on 14 January 2019).

7. Adams, R.; Bischof, L. Seeded region growing. IEEE Trans. Pattern Anal. Mach. Intell. 1994, 16, 641-647. [CrossRef]

8. Otsu, N. A threshold selection method from gray-level histograms. IEEE Trans. Syst. Man Cybern. 1979, 9, 62-66. [CrossRef]

9. Himmi, S.K.; Yoshimura, T.; Yanase, Y.; Mori, T.; Torigoe, T.; Imazu, S. Wood anatomical selectivity of drywood termite in the nest-gallery establishment revealed by X-ray tomography. Wood Sci. Technol. 2016, 50, 631-643. [CrossRef]

10. Rust, M.K.; Paine, E.O.; Reierson, D.A. Evaluation of freezing to control wood-destroying insects (Isoptera, Coleoptera). J. Econ. Entomol. 1997, 90, 1215-1221. [CrossRef]

11. Pinniger, D. Saving our treasures-controlling museum pests with temperature extremes. Pesticide Outlook 2003, 14, 10-11. [CrossRef]

12. Berzolla, A.; Reguzzi, M.C.; Chiappini, E. Controlled atmospheres against insect pests in museums: A review and some considerations. J. Entomol. Acarol. Res. 2011, 43, 197-204. [CrossRef]

13. Iwamoto, J.; Kenmochi, Y.; Kotani, K.; Nagasawa, I. Extraction of a 3D graph structure of wormholes in a wooden statue of Buddha by X-ray CT image analysis. In Proceedings of the Fifth Asian Conference on Computer Vision, ACCV2002, Melbourne, Australia, 23-25 January 2002; Volume 2, pp. 864-870.

14. Kozachuk, M.; Suda, A.; Ellis, L.; Walzak, M.; Biesinger, M.; Macfie, S.; Hudson, R.; Nelson, A.; Martin, R.; Heginbotham, A. Possible Radiation-Induced Damage to the Molecular Structure of Wooden Artifacts Due to Micro-Computed Tomography, Handheld X-Ray Fluorescence, and X-Ray Photoelectron Spectroscopic Techniques. J. Conserv. Mus. Stud. $2016,14,1$.

15. Krügener, K.; Stübling, E.M.; Jachim, R.; Kietz, B.; Koch, M.; Viöl, W. THz tomography for detecting damages on wood caused by insects. Appl. Optics 2019, 58, 6063-6066. [CrossRef]

16. Bentivoglio-Ravasio, B.; Marconi, E.; Trotta, L.; Dreossi, D.; Sodini, N.; Mancini, L.; Zanini, F.; Tonini, C. Synchrotron radiation microtomography of musical instruments: A non-destructive monitoring technique for insect infestations. J. Entomol. Acarol. Res. 2011, 43, 149-155. [CrossRef]

17. What Is Integrated Pest Management? Available online: https://ipminstitute.org/what-is-integrated-pest-management/ (accessed on 5 April 2021).

18. Introduction to Integrated Pest Management. Available online: https://www.epa.gov/ipm/introduction-integrated-pestmanagement (accessed on 5 April 2021).

19. Querner, P. Insect pests and integrated pest management in museums, libraries and historic buildings. Insects 2015, 6, 595-607. [CrossRef] [PubMed]

20. McMahan, E. Laboratory Studies of Colony Establishment and Development in Cryptotermes brevis (Walker) (Isoptera: Kalotermitidae). Proc. Hawaii. Entomol. Soc. 1962, 18, 145-153.

21. Steward, R. Microclimate and colony foundation by imago and neotenic reproductives of dry-wood termite species (Cryptotermes sp.) (Isoptera: Kalotermitidae). Sociobiology 1983, 7, 311-332.

22. Keller, L. Queen lifespan and colony characteristics in ants and termites. Insectes Sociaux 1998, 45, 235-246. [CrossRef]

23. Korb, J.; Weil, T.; Hoffmann, K.; Foster, K.R.; Rehli, M. A gene necessary for reproductive suppression in termites. Science 2009, 324, 758. [CrossRef] [PubMed]

24. Vankin, D. How does the Getty Battle BUGS? Squirrel-hair dusters and dental picks, for starters. Los Angeles Times 2021. Available online: https:/ / www.latimes.com/entertainment-arts / story/2021-04-22/getty-museum-covid-closure-moth-remediation (accessed on 22 April 2021). 